\title{
A system for risk stratification and prioritization of breast cancer surgeries delayed by the COVID-19 pandemic: preparing for re-entry
}

\author{
Barbara L. Smith ${ }^{1}$ (D . Anvy Nguyen ${ }^{1} \cdot$ Jenna E. Korotkin ${ }^{1} \cdot$ Bridget N. Kelly $^{1} \cdot$ Michelle C. Specht $^{1} \cdot$ Laura M. Spring $^{2}$. \\ Beverly Moy ${ }^{2} \cdot$ Steven J. Isakoff ${ }^{2} \cdot$ Michele A. Gadd $^{1}$
}

Received: 6 May 2020 / Accepted: 6 July 2020 / Published online: 25 July 2020

(c) Springer Science+Business Media, LLC, part of Springer Nature 2020

\begin{abstract}
Purpose During the COVID-19 pandemic, most breast surgery for benign and malignant conditions has been postponed, creating a backlog of patients who will need surgery. A fair and transparent system for assessing the risk of further delaying surgery for individual patients to prioritize surgical scheduling is needed.

Methods Factors related to risk of delaying surgery for breast patients were identified. Scores were assigned to each factor, with higher scores indicating a greater risk from delaying surgery. REDCap and Microsoft Excel tools were designed to track and score delayed patients.

Results Published data and multidisciplinary clinical judgement were used to assign risk scores based on patient and tumor factors, length of delay, and tumor response to preoperative therapy. Patients completing neoadjuvant chemotherapy were assigned the highest scores as their options for delaying surgery are most limited. Among patients receiving neoadjuvant endocrine therapy or no medical therapy, higher scores were assigned for low-estrogen receptor or high-genomic risk scores, higher grade, larger tumors, younger age and longer delay. High priority scores were assigned for progression during preoperative therapy. Low scores were assigned for re-excisions, atypical lesions and other benign indications. There was good agreement of the tool's ranking of sample patients with rankings by experienced clinicians. The tool generates risk-stratified patient lists by surgeon or institution to facilitate assignment of surgery dates.

Conclusions This tool generates a clinically consistent, risk-stratified priority list of breast surgical procedures delayed by the COVID-19 pandemic. This systematic approach may facilitate surgical scheduling as conditions normalize.
\end{abstract}

Keywords Breast surgery $\cdot$ Clinical decision-making · COVID-19 $\cdot$ Surgical priority $\cdot$ Scoringsystem $\cdot$ Surgical scheduling

\section{Introduction}

During the COVID-19 pandemic, surgery for breast cancer and other breast conditions is severely restricted as operating rooms become ICU's, OR staff are deployed for urgent COVID-19 care, and preservation of personal protection equipment and critical care medications is necessary. Many breast cancer patients are being managed with neoadjuvant endocrine therapy or chemotherapy to delay surgery. There

Barbara L. Smith

blsmith1@mgh.harvard.edu

1 Division of Surgical Oncology, Massachusetts General Hospital, MGH Center for Breast Cancer, Yawkey 9A, 55 Fruit St, Boston, MA 02114, USA

2 Department of Hematology Oncology, Massachusetts General Hospital, Boston, MA, USA are inflexible limits to the duration of most neoadjuvant chemotherapy regimens, and surgery will become urgent for these patients. Some patients receiving neoadjuvant endocrine therapy may develop progressive disease, increasing the urgency for their surgery.

It is expected that OR availability for breast surgery will increase only gradually. When access improves, the significant backlog of delayed patients will compete with newly diagnosed patients for operating room time. Although broad guidelines have been issued for initial prioritization of surgery for breast conditions [1,2] and for other surgical patients [3], there is no clear guidance for determining order of surgery among a large number of delayed breast surgery patients. A system for assessing the risk of further delaying surgery and prioritizing access to the OR is needed. Fairness and transparency must be central features of such a system. 
To address this need, we created a system for scoring risk of delaying breast surgery to help prioritize assignment of surgical dates. Using published data and multidisciplinary clinical judgement, scores were assigned to patient and tumor risk factors and to length of delay. Patients were assessed at diagnosis and for response during treatment to determine the safety of additional delay versus the urgency of proceeding with surgery.

Tools were created to allow rapid entry of patient data, with automatic calculation and updating of risk scores, to generate risk-stratified lists of breast patients whose surgery has been delayed.

\section{Methods}

Factors related to risk of delaying surgery for breast surgery were identified by a multidisciplinary breast team and scores assigned based on the estimated contribution of each factor to risk. Factors used for T1-2N0, estrogen-receptor positive $(\mathrm{ER}+)$ patients included:

- Endocrine responsiveness estimated by genomic risk testing [4-6] if performed, or by percentage of cells staining $\mathrm{ER}+$ and/or progesterone receptor positive (PR+), and intensity of immunohistochemistry (IHC) staining

- Tumor grade

- Tumor size

- Axillary node status

- Patient age

- Time since biopsy

- Evidence of progression on follow up imaging and/or physical examination

For patients receiving neoadjuvant chemotherapy, chemotherapy regimen received, date of final chemotherapy dose and ER status were recorded.

Positive lumpectomy margins and non-malignant conditions were assigned low scores but included to create a comprehensive list of delayed surgeries. Factors scored for patients without cancer included presence of atypical ductal hyperplasia $(\mathrm{ADH})$ or other atypia.

Additional data collected included surgeon name and institution to create risk stratified lists by surgeon or by institution. Tools were prepared in both REDCap [7, 8] and Microsoft Excel formats.

To compare the priority rankings generated by the scoring tool with ranking by clinical judgement, we created 10 hypothetical patients with newly diagnosed ER+ breast cancers. A second scenario included updated information on the initial 10 patients' responses to treatment and 5 newly diagnosed patients. Priority ranking for surgery calculated by the tool was compared with priority rankings by 3 breast surgeons who had not participated in creating the scoring system.

\section{Results}

\section{Assignment and justification of risk scores}

Patient and tumor factors thought to impact risk of delaying breast surgery were identified by a multidisciplinary breast team and each assigned a score, with higher scores indicating greater potential risk from delaying surgery. Scores were assigned using published data when available (Table 1), and using multidisciplinary clinical judgement where data was lacking. Score assignments assumed that patients completing neoadjuvant chemotherapy should proceed with surgery on schedule except under the most extreme resource limitations. ER- tumors received priority over ER+ and human epidermal growth factor 2 positive (HER2+) tumors, since endocrine therapy or anti-HER 2 therapy might be used to delay surgery for these patients. Assignments assumed that most ER+, T1-2N0-1 patients can defer surgery for several months with neoadjuvant endocrine therapy, but must be monitored and proceed urgently to surgery or other systemic therapy for progression. It was assumed that most surgery for positive lumpectomy margins, risk reduction, benign lesions and non-reconstruction cosmetic reasons can be deferred until COVID-19 delayed cancers have been treated.

Scores were assigned to separate patients into 3 groups and create a range of scores within each group for eventual assignment of surgical dates: (1) Very urgent (score $\geq 30$ ), narrow window for safe surgery, for example, patients completing neoadjuvant chemotherapy; (2) Limited delay acceptable (score 10-29), but may become urgent, for example, patients receiving neoadjuvant endocrine therapy and (3) Lowest priority (score $<10$ ), likely safe to wait, for example, re-excisions, atypical lesions, prophylactic mastectomies, benign lesions and cosmetic procedures (Fig. 1). Very urgent patients will generally have surgery within $2-4$ weeks of completion of chemotherapy as was done prior to the pandemic. Limited delay acceptable patients will generally wait 2-4 months, or longer if they continue to respond to neoadjuvant endocrine therapy. Lowest priority patients will wait until conditions allow elective surgery to resume. The scores assigned to each patient, tumor, delay and response measure are shown in Table 2.

\section{ER+ tumors receiving neoadjuvant endocrine therapy or no neoadjuvant therapy}

The majority of patients whose surgery is being delayed have T1-2N0-1, ER+, HER2- breast cancers. Most are receiving neoadjuvant endocrine therapy to allow postponement of 
Table 1 Response rates to neoadjuvant endocrine therapy regimens in early stage ER+ breast cancer

\begin{tabular}{|c|c|c|c|c|c|c|c|c|c|}
\hline Author year & \# pts & Tumor stage & Menopause status & Regimen & $\mathrm{N}$ & Therapy duration & $\begin{array}{l}\text { Responding } \\
(\%)\end{array}$ & $\begin{array}{l}\text { Stable } \\
(\%)\end{array}$ & $\begin{array}{l}\text { Progressing } \\
(\%)\end{array}$ \\
\hline \multirow[t]{3}{*}{ Ellis (2011) } & \multirow[t]{3}{*}{349} & \multirow[t]{3}{*}{ T2-4c, N0-3, M0 } & \multirow[t]{3}{*}{ Post } & Anastrozole & 114 & \multirow[t]{3}{*}{$16-18 w$} & 74.6 & 17.5 & 7.9 \\
\hline & & & & Exemestane & 114 & & 68.4 & 24.6 & 7 \\
\hline & & & & Letrozole & 121 & & 78.5 & 16.5 & 5 \\
\hline Iwata (2019) & 295 & $\mathrm{~T} 1 \mathrm{c}-\mathrm{T} 2, \mathrm{cN} 0, \mathrm{M} 0$ & Post & Letrozole & 295 & $24-28 w$ & 45 & 51 & 4 \\
\hline \multirow[t]{3}{*}{ Smith (2005) } & \multirow[t]{3}{*}{282} & \multirow[t]{3}{*}{ T1-4, N0-3, M0 } & \multirow[t]{3}{*}{ Pre and Post } & Anastrozole & 94 & \multirow[t]{3}{*}{$3 \mathrm{mo}$} & 40.4 & 50 & 9.6 \\
\hline & & & & Tamoxifen & 96 & & 37.5 & 57.3 & 5.2 \\
\hline & & & & Combination & 92 & & 43.5 & 51.1 & 5.4 \\
\hline \multirow[t]{2}{*}{ Johnston (2019) } & \multirow[t]{2}{*}{279} & \multirow[t]{2}{*}{ T2-T4, M0 } & \multirow[t]{2}{*}{ Post } & Letrozole & 93 & \multirow[t]{2}{*}{$14-16 w$} & 50 & 45 & 5 \\
\hline & & & & Palbo + Let & 186 & & 54 & 43 & 3 \\
\hline \multirow[t]{3}{*}{ Allevi (2013) } & \multirow[t]{3}{*}{118} & \multirow[t]{3}{*}{ T2-4, N0-1, M0 } & \multirow[t]{3}{*}{ Post } & \multirow[t]{3}{*}{ Letrozole } & 40 & $4 \mathrm{mo}$ & 45 & 45 & 10 \\
\hline & & & & & 38 & $8 \mathrm{mo}$ & 87 & 10 & 3 \\
\hline & & & & & 40 & $12 \mathrm{mo}$ & 95 & 5 & 0 \\
\hline Toi (2011) & 104 & T2-3, N0-1, M0 & Post & Exemestane & 104 & $6 \mathrm{mo}$ & 57 & 39 & 4 \\
\hline Olson (2009) & 100 & T2-4, N0-2, M0 & Post & Letrozole & 100 & $16-24 w$ & 62 & 26 & 12 \\
\hline \multirow{2}{*}{$\begin{array}{l}\text { Akashi-Tanaka } \\
\text { (2009) }\end{array}$} & \multirow[t]{2}{*}{87} & \multirow[t]{2}{*}{$\mathrm{T} 2-\mathrm{T} 4$} & \multirow[t]{2}{*}{ Post } & Anastrozole & 48 & \multirow[t]{2}{*}{$4 \mathrm{mo}$} & \multirow[t]{2}{*}{42.5} & \multirow[t]{2}{*}{50.5} & \multirow[t]{2}{*}{7} \\
\hline & & & & Tamoxifen & 39 & & & & \\
\hline Fontein (2014) & 79 & $\mathrm{~T} 2-\mathrm{T} 4, \mathrm{~N} 0-3, \mathrm{M} 0$ & Post & Exemestane & 77 & $6 \mathrm{mo}$ & 65 & 30 & 5 \\
\hline Ueno (2014) & 61 & T2-3, N0-2, M0 & Post & Exemestane & 61 & $6 \mathrm{mo}$ & 52.5 & 39.3 & 8.2 \\
\hline Barnadas (2009) & 54 & $\mathrm{~T} 2-4 \mathrm{c}, \mathrm{N} 1-2, \mathrm{M} 0$ & Post & Exemestane & 54 & $6 \mathrm{mo}$ & 61 & 35 & 4 \\
\hline
\end{tabular}

Progression defined as 20-25\% increase in tumor area or appearance of new lesions

Palbo Palbociclib, Let letrozole

surgery for several months. Preoperative endocrine therapy is well tolerated and increases rates of breast conservation $[9,10]$. While pathologic complete response rates are low, few tumors will progress [9, 11-22]. Although the duration of neoadjuvant endocrine therapy was 4-6 months in most trials [23], preoperative treatment for 12 months or more is possible, often with continued response. Overall response rates to letrozole in postmenopausal women rose from $49.6 \%$ at 4 months to $95 \%$ at 12 months, with pCR rates of $2.5 \%$ at 4 months and $17.5 \%$ at 12 months [15].

Scores for the following factors were assigned to T1-2N0, $\mathrm{ER}+$, HER2- patients to predict risk of delaying surgery.

\section{Endocrine responsiveness score}

Oncotype score has been validated as a predictor of benefit of endocrine therapy in node-negative [4, 24-27] and nodepositive [26, 28] ER+, HER2- early-stage breast cancers, with correlation $[18,20]$ and validation [12] of Oncotype score as a predictor of response to neoadjuvant endocrine therapy. Rates of progression in the TransNEOS study were $1 \%$ with Oncotype scores of $0-18,4 \%$ with scores of $19-30$, but $17 \%$ with scores $\geq 31$ [12]. MammaPrint [5], or EndoPredict [6] genomic risk tests have also been shown to predict outcomes with endocrine therapy.
Endocrine responsiveness was scored by genomic risk testing when performed, or by strength of ER and PR expression by IHC. The tool assigned a significantly higher risk score for Oncotype scores $\geq 31$ or high risk on MammaPrint or EndoPredict testing. For patients without genomic testing, percentage of cells staining ER+ and intensity of IHC staining was used. A high score was assigned for only faint/ weak ER-staining at any percentage, for moderate or strong staining in only $1-10 \%$ of cells, or for ER- tumors. As PR expression is dependent on ER expression, weak or absent PR expression was assigned a higher score.

\section{Tumor grade score}

Higher breast tumor grade is associated with a poorer prognosis [29], and higher scores were assigned for higher grade. For tumors containing a mixture of grades or reported as a range of grades (eg grade 2-3), score was assigned using the highest grade present.

\section{Tumor size score}

Higher scores were assigned to larger invasive tumors. While risk of finding invasive tumor for DCIS on core biopsy increases with longer surgical delay [30], trials of active surveillance without immediate surgery for DCIS are underway 


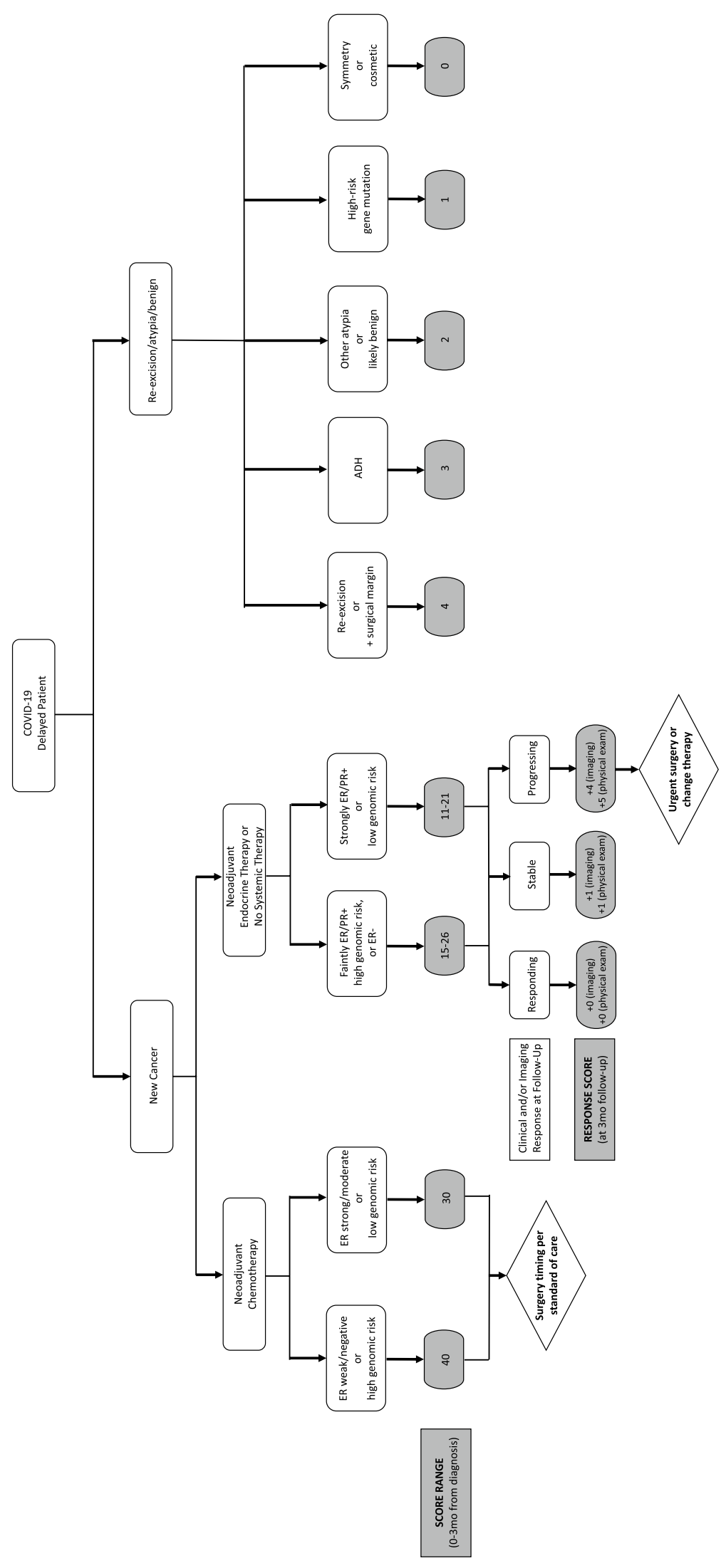

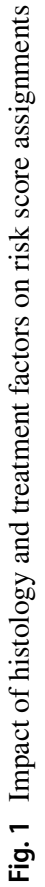


Table 2 Score assignments for factors related to risk of delaying breast surgery

Risk factor

Risk score

Indication priority score-all patients

Indication score

Cancer-neoadjuvant chemotherapy 30

Cancer-neoadjuvant endocrine therapy or ER- DCIS or ER-, no chemotherapy 10

Re-excision, positive lumpectomy margin 4

$\mathrm{ADH}$

Other atypia/probably benign $\quad 2$

High-risk gene mutation $\quad 1$

Symmetry/cosmetic 0

Scored only for cancer patients receiving neoadjuvant endocrine therapy

Endocrine sensitivity score

If genomic risk testing done

Genomic risk test score-Oncotype DX

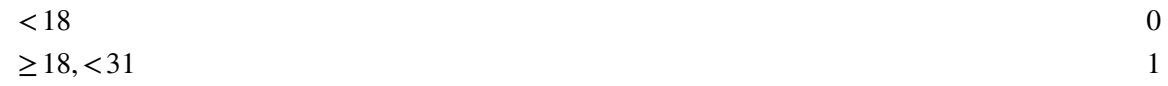

Genomic risk test score-MammaPrint, EndoPredict, or other

Low risk 0

High risk 5

If no genomic risk testing done

ER strength score

$\geq 50 \%$ strong/moderate $\quad 0$

$11-49 \%$ strong/moderate $\quad 1$

Any $\%$ faint or $1-10 \%$ strong/moderate or ER- 4

PR strength score

Strong/moderate $\quad 0$

Weak/negative 1

Tumor grade score

1

22

323

Tumor size $(\mathrm{cm})$ score

DCIS

Microinvasion $(\leq 0.1) \quad 1$

$>0.1, \leq 1.0 \quad 1$

$>1.0, \leq 2.0 \quad 2$

$>2.0, \leq 3.0 \quad 3$

$>3.0 \quad 4$

Patient age score

$\begin{array}{ll}\geq 70 & 0 \\ \geq 50,<70 & 1 \\ \geq 35,<50 & 3 \\ <35 & 4\end{array}$

Delay score

Time since biopsy

$\geq 0,<3$ months $\quad 0$

$\geq 3,<4$ months 1

$\geq 4,<6$ months $\quad 2$

$\geq 6$ months 3

Imaging response score 
Table 2 (continued)

\begin{tabular}{lc}
\hline Risk factor & Risk score \\
\hline Stable & 1 \\
Progressing any site & 4 \\
Physical exam response score & \\
Not palpable and not palpable at diagnosis & 0 \\
Responding & 0 \\
Stable & 1 \\
Progressing any site & 5 \\
Scored only for cancer patients receiving neoadjuvant chemotherapy & \\
ER score-neoadjuvant chemotherapy patients & 0 \\
ER strong/moderate or low genomic risk & 10 \\
ER weak/negative or high genomic risk & \\
Total risk score & \\
Total score & \\
\hline
\end{tabular}

$E R$ estrogen receptor, $P R$ progesterone receptor

$[31,32]$. Prognosis for DCIS or DCIS with microinvasion is excellent and they are assigned lower scores than invasive cancers, DCIS with microinvasion higher than DCIS alone.

\section{Patient age score}

As there is limited data on the efficacy of prolonged neoadjuvant endocrine therapy in premenopausal women, higher priority scores were assigned to younger women. In one study, response rates at 24 weeks in premenopausal women were $70.4 \%$ with anastrozole + goserelin and $50.5 \%$ with tamoxifen + goserelin [33]. Response rates increased with longer duration of endocrine therapy for both anastrozole and tamoxifen.

\section{Duration of delay score}

A higher scores were assigned to patients with longer times between diagnostic biopsy and evaluation, increasing with each 3-month increment of delay.

\section{Progression/response score}

Rates of tumor progression in studies of neoadjuvant endocrine therapy range from 3-12\% (Table 1) [9, 11-22], but are as high as $17 \%$ in a subset of patients with high Oncotype scores [12]. Patients whose tumors are progressing should undergo surgery as soon as possible. To identify progression, we recommend reassessment with physical exam 2-3 months after initiation of neoadjuvant endocrine therapy, potentially with repeat imaging. The score assigned at diagnosis is adjusted significantly upward for progression on physical examination and/or imaging, with progression detectable on physical examination given a higher score. Both imaging and examination scores are added to the total score, creating a high priority for progressing tumors. Stable tumors are given a low progression score and no points are added for responding tumors. Patients unable to tolerate neoadjuvant endocrine therapy should be followed closely and undergo surgery for progression.

\section{Other patient and tumor factors}

Node status at diagnosis is recorded but does not contribute to the score assigned at diagnosis. Although node status may be used in deciding between neoadjuvant chemotherapy or neoadjuvant endocrine therapy, once neoadjuvant endocrine therapy is selected, we believe the scoring of factors described above and scoring of response versus progression appropriately prioritizes patients for surgery.

\section{ER-, HER2+, and higher stage patients receiving neoadjuvant chemotherapy}

Patients receiving neoadjuvant chemotherapy generally have the highest risk breast cancers. In contrast to patients receiving neoadjuvant endocrine therapy, the toxicity of neoadjuvant chemotherapy precludes prolonged treatment. After completing the standard course of chemotherapy, patients should ideally have surgery within a narrow time frame that allows enough time for resolution of neutropenia and other toxicities, but not so long that tumor progression could occur.

Key data recorded for neoadjuvant chemotherapy patients are chemotherapy regimen and date of last treatment, as these define the safe window for surgery. A very high score was assigned to all neoadjuvant chemotherapy patients, 
which always puts them at the top of the priority list for surgery. ER- tumors were given higher priority scores than ER+ tumors, where endocrine therapy might safely allow further delay of surgery. This system does not provide detailed prioritization among patients receiving neoadjuvant chemotherapy, as complex individual factors determine risk of delaying surgery in these patients. We recommend multidisciplinary review on a case-by-case basis.

\section{Positive lumpectomy margins, atypical lesions, benign and prophylactic surgery patients}

The tool creates a comprehensive prioritized list of all patients whose breast surgery has been delayed. Postponing surgery for patients with positive lumpectomy margins has been deemed reasonable [1] as extent of residual disease is likely low and other tumor properties are known from the initial surgery. A score was assigned placing their priority below that of other cancers but above that of non-malignant conditions.

Patients without malignancy were assigned scores reflecting their lower risk. Atypical ductal hyperplasia (ADH) on core biopsy is scored highest, as the upgrade rate to DCIS or invasive carcinoma on excisional biopsy is approximately $20 \%$ [34, 35]. Other atypical lesions (LCIS, ALH, FEA, radial scars) with lower upgrade rates $[34,36]$ receive the next highest score. Prophylactic mastectomies were scored below atypical lesions but before surgery for other benign conditions.

\section{Validation}

To determine whether this tool produced priority scores consistent with clinical judgement, we created 10 hypothetical patients with a variety of newly diagnosed ER+ breast cancers. Three breast surgeons who had not participated in creating the scoring system reviewed patient data and ranked patients from lowest to highest priority for surgery. The rankings produced by the clinicians were nearly identical to the ranking produced by the tool (Table 3 ).

To simulate the mix of delayed and newly diagnosed patients expected when screening resumes, each surgeon reviewed updated records of the initial 10 patients that included examination and imaging findings 3 months after initiation of neoadjuvant endocrine therapy. Intermingled with these delayed patients were 5 newly diagnosed patients. Clinicians were not given rules for prioritizing delayed versus new patients. They again ranked priority for surgery. There was less consensus among surgeons in ranking this group, but assignments to low, medium and high priority groups were very similar to assignments generated by the tool; surgeons 1, 2 and 3 agreed with the scoring system in $13 / 15,14 / 15$ and $11 / 15$ patients, respectively.

\section{Discussion}

Many patients with breast cancer, atypical lesions and other breast conditions have had their surgery postponed during the COVID-19 pandemic. A systematic approach is needed for surgeons and institutions to track their delayed and newly diagnosed breast patients, with a fair and transparent process to prioritize patients for surgery. Assignment of OR priority must consider nuances of each patient's circumstances.

We describe a tool that generates an objective, risk-stratified list of all types of benign and malignant breast surgical cases delayed during the COVID-19 pandemic. It provides a detailed initial stratification of a patient's risk based on familiar clinical factors, and updates priority based on delay time and any progression of disease. It produces priority rankings consistent with the priority categories of the Consortium recommendations [1]. Importantly, it generates a range of scores within the large cohort of ER+/HER2- cancers (Consortium Priorities B3, C1 and C2) to help prioritize assignment of surgery dates. Priority ranking of test $\mathrm{ER}+$ cancer patients by the tool agreed well with rankings by experienced breast surgeons.

The tool was prepared in REDCap and Microsoft Excel formats to accommodate surgeon preference and different practice settings. Both options have a user-friendly interface suitable for use in small or large practices. Priority lists can be generated by surgeon or by institution. Data entry for an $\mathrm{ER}+$ patient generally takes less than a minute. Even less data entry is required for neoadjuvant chemotherapy patients and for patients with benign conditions.

A limitation of this tool is that assignment of risk scores was based largely on clinical judgement and multidisciplinary discussion. Unfortunately, there is little data on outcomes of prolonged neoadjuvant endocrine therapy in early stage breast cancer, particularly in premenopausal patients. Risks of delaying DCIS surgery, re-excision procedures or diagnostic excisional biopsies for atypia are largely unknown. However, precedent exists for using clinical judgement to create breast cancer decision aids, for example the Adjuvant! tool for estimating chemotherapy benefit for individual breast cancer patients [37].

A standardized scoring system will provide needed data on the effects of delaying breast surgery. New information about outcomes of neoadjuvant endocrine therapy in early stage and premenopausal patients can be gained, including how patient and tumor factors impact rates of response or progression. With data collected now, scoring systems can be refined for use in future situations where surgery must be delayed.

It is important to note that this tool is not a substitute for clinical judgment or multidisciplinary consultation in managing breast patients during the COVID-19 pandemic. While 
Table 3 Priority ranks generated by the scoring system compared with priority ranks generated by experienced breast surgeons

\begin{tabular}{|c|c|c|c|c|c|c|}
\hline \multirow[t]{2}{*}{ Priority rank } & \multicolumn{3}{|c|}{ Patient (system score) } & \multicolumn{2}{|c|}{ Scoring system } & \multirow[t]{2}{*}{ Test patient and tumor characteristics } \\
\hline & Surgeon 1 & Surgeon 2 & Surgeon 3 & Patient & Score & \\
\hline 1 & $\mathrm{~F}(18)$ & $\mathrm{H}(20)$ & $\mathrm{H}(20)$ & $\mathrm{H}$ & 20 & $\mathrm{H}: 45$ yo, $2.5 \mathrm{~cm}$ grade $2 \mathrm{IDC}$, moderate ER+, PR-, N0 \\
\hline 2 & $\mathrm{H}(20)$ & $\mathrm{F}(18)$ & $\mathrm{F}(18)$ & $\mathrm{F}$ & 18 & F: 49 yo, $1.8 \mathrm{~cm}$ grade 2 IDC, ER, Oncotype $=25, \mathrm{~N} 0$ \\
\hline 3 & $\mathrm{G}(16)$ & A (17) & $\mathrm{G}(16)$ & A & 17 & A: 49 yo, $1.2 \mathrm{~cm}$ grade 2 IDC, strongly ER/PR+, N0 \\
\hline 4 & I (14) & $\mathrm{G}(16)$ & A (17) & $\mathrm{G}$ & 16 & G: 68 yo, $1.3 \mathrm{~cm}$ grade $3 \mathrm{IDC}$, strongly ER/PR+, N0 \\
\hline 5 & A (17) & I (14) & $\mathrm{D}(13)$ & I & 14 & I: 55 yo, $0.9 \mathrm{~cm}$ grade 2 IDC, ER+ Oncotype $=16, \mathrm{~N} 0$ \\
\hline 6 & $\mathrm{C}(14)$ & $\mathrm{C}(14)$ & I (14) & $\mathrm{C}$ & 14 & C: 63 yo, $0.9 \mathrm{~cm}$ grade 2 ILC, ER+Oncotype $=11, \mathrm{~N} 0$ \\
\hline 7 & $\mathrm{~B}(12)$ & $\mathrm{D}(13)$ & $\mathrm{C}(14)$ & $\mathrm{D}$ & 13 & D: 60 yo, $1.4 \mathrm{~cm}$ grade $1 \mathrm{DCIS}+\mathrm{mi}$, strongly ER/PR+, N0 \\
\hline 8 & $\mathrm{D}(13)$ & $\mathrm{E}(13)$ & $\mathrm{E}(13)$ & $\mathrm{E}$ & 13 & E: 62 yo, $1.0 \mathrm{~cm}$ grade 2 DCIS, strongly ER,$+ \mathrm{N} 0$ \\
\hline 9 & E (13) & B (12) & B (12) & B & 12 & B: 90 yo, $1.0 \mathrm{~cm}$ grade $1 \mathrm{IDC}$, strongly ER/PR+, N0 \\
\hline 10 & $\mathrm{~J}(11)$ & $\mathrm{J}(11)$ & $\mathrm{J}(11)$ & $\mathrm{J}$ & 11 & J: 79 yo, grade 1 DCIS, strongly ER/PR+, N0 \\
\hline
\end{tabular}

Scores of 18 or higher were considered highest risk, 15-17 considered medium risk, and 14 or lower considered lowest risk

yo years old, $E R$ estrogen receptor, $P R$ progesterone receptor, IDC invasive ductal cancer, DCIS ductal carcinoma in situ; mi: microinvasion, ILC invasive lobular cancer

this tool can help manage and prioritize large numbers of delayed breast surgery patients, it remains essential to consider individual patient factors and conditions at individual practice locations. Resumption of breast surgery will be concurrent with resumption of many other hospital activities. Use of hospital resources will need to be balanced across specialties and with consideration of personnel and resource constraints in the operating room, hospital and community [38]. For each surgical procedure, the patient's health status, including risk of having or acquiring a SARS-CoV-2 infection must be considered. Prioritization of breast surgery in this environment will require ongoing multidisciplinary discussion.

This risk stratification tool is undergoing additional testing at other sites, and was included in the COVID-19 Pandemic Breast Cancer Consortium's Considerations for Re-entry [39] issued 5/15/2020 by the Breast Cancer Consortium (American College of Radiology, American College of Surgeons Commission on Cancer, National Accreditation Program for Breast Centers, American Society of Breast Surgeons, American Society of Clinical Oncology and the National Comprehensive Cancer Network and the Society of Surgical Oncology).

Data availaibility Copies of the REDCap and Excel databases are available to individuals or institutions without charge via the Mass General Division of Surgical Oncology website. https://www.massg eneral.org/surgical-oncology/about/news-and-events/re-entry-tool-forbreast-surgeons/.

\section{Compliance with ethical standards}

Conflict of interest The authors report no conflict of interest relevant to this publication. Drs. Smith, Nguyen, Specht, Gadd, Moy and Ms. Korotkin and Ms. Kelly declare they have no conflict of interest. Dr.
Spring reports consulting (Novartis), travel (Tesaro), and research funding to the institution (Tesaro, Merck). Dr. Isakoff reports consulting (Abbvie, OncoPrep) and research funding to institution (Abbvie, AstraZeneca, Genetech, Merck, OncoPrep, Pharmamar).

\section{References}

1. Dietz JR, Moran MS, Isakoff SJ et al (2020) Recommendations for prioritization, treatment, and triage of breast cancer patients during the COVID-19 pandemic the COVID-19 pandemic breast cancer consortium. Breast Cancer Res Treat. https://doi.org/10.1007/ s10549-020-05644-z

2. Daraï E, Mathelin C, Gligorov J (2020) Breast cancer management during the COVID 19 pandemic: french guidelines. Eur J Breast Health. https://doi.org/10.5152/ejbh.2020.200420

3. Prachand VN, Milner R, Angelos P, Posner MC, Fung JJ, Agrawal N, Jeevanandam V, Matthews JB (2020) Medically-necessary, time-sensitive procedures: a scoring system to ethically and efficiently manage resource scarcity and provider risk during the COVID-19 pandemic. J Am Coll Surg. https://doi.org/10.1016/j. jamcollsurg.2020.04.011

4. Paik S, Shak S, Tang G, Kim C, Baker J, Cronin M, Kaehner FL, Walker MG, Watson D, Park T, Hiller W, Fisher ER, Wickerham DL, Bryan J, Wolmark N (2004) A multigene assay to predict recurrence of tamoxifen-treated, node-negative breast cancer. $\mathrm{N}$ Engl J Med 351(27):2817-2826. https://doi.org/10.1056/NEJMo a041588

5. van de Vijver MJ, He YD, van't Veer LJ et al (2002) A geneexpression signature as a predictor of survival in breast cancer. $\mathrm{N}$ Engl J Med 347:1999-2009

6. Dubsky P, Filipits M, Jakesz R et al (2013) EndoPredict improves the prognostic classification derived from common clinical guidelines in ER-positive, HER2-negative early breast cancer. Ann Oncol 24(3):640-647. https://doi.org/10.1093/annonc/mds334

7. Harris PA, Taylor R, Minor BL, Elliot V, Fernandez M, O’Neal L, McLeod L, Delacqua G, Delacqua F, Kirby J, Duda SN, REDCap Consortium (2019) The REDCap consortium: building an international community of software partners. J. Biomed Inform. https ://doi.org/10.1016/j.jbi.2019.103208 
8. Harris PA, Taylor R, Thielke R, Payne J, Gonzalez N, Conde JG (2009) Research electronic data capture (REDCap)—A metadata-driven methodology and workflow process for providing translational research informatics support. J Biomed Inform 42(2):377-381

9. Eiermann W, Paepke S, Llombart-Cussac A, Eremin J, Vinholes J, Mauriac L, Ellis M, Lassus M, Chaudri-Ross HA, Dugan M, Borgs M, Semiglazov V; Letrozole Neo-Adjuvant Breast Cancer Study Group (2001) Preoperative treatment of postmenopausal breast cancer patients with letrozole: a randomized doubleblind multicenter study. Ann Oncol 12:1527-1532. https://doi. org/10.1023/a:1013128213451

10. Cataliotti L, Buzdar AU, Noguchi S, Bines J, Takatsuka Y, Petrakova K, Dube P, de Oliveira CT (2006) Comparison of anastrozole versus tamoxifen as preoperative therapy in postmenopausal women with hormone receptor-positive breast cancer: the preoperative "Arimidex" compared to tamoxifen (PROACT) trial. Cancer 106(10):2095-2103. https://doi.org/10.1002/cncr.21872

11. Ellis MJ, Suman VJ, Hoog J et al (2011) Randomized phase II neoadjuvant comparison between letrozole, anastrozole, and exemestane for postmenopausal women with estrogen receptorrich stage 2 to 3 breast cancer: clinical and biomarker outcomes and predictive value of the baseline PAM50-based intrinsic subtype-ACOSOG Z1031. J Clin Oncol 29(17):2342-2349. https:// doi.org/10.1200/JCO.2010.31.6950

12. Iwata H, Masuda N, Yamamoto Y, Fujisawa T, Toyama T, Kashiwaba M, Ohtani S, Taira N, Sakai T, Hasegawa Y, Nakamura R, Akabane H, Shibahara Y, Sasano H, Yamaguchi T, Sakamaki K, Bailey H, Cherbavas DB, Jakubowski DM, Sugiyama N, Chao C, Ohashi Y (2019) Validation of the 21-gene test as a predictor of clinical response to neoadjuvant hormonal therapy for ER+, HER2-negative breast cancer: the TransNEOS study. J Breast Cancer Res Treat 173:123-133.

13. Smith IE, Dowsett M, Ebbs SR, Dixon JM, Skene A, Blohmer JU, Ashley SE, Francis S, Boeddinghaus I, Walsh G, Group IT (2005) Neoadjuvant treatment of postmenopausal breast cancer with anastrozole, tamoxifen, or both in combination: the Immediate Preoperative Anastrozole, Tamoxifen, or Combined with Tamoxifen (IMPACT) multicenter double-blind randomized trial. J Clin Oncol 23(22):5108-5116. https://doi.org/10.1200/ JCO.2005.04.005

14. Johnston S, Puhalla S, Wheatley D et al (2019) Randomized phase II study evaluating palbociclib in addition to letrozole as neoadjuvant therapy in estrogen receptor-positive early breast cancer: PALLET trial. J Clin Oncol 37:178-189. https://doi.org/10.1200/ JCO.18.01624

15. Allevi G, Strina C, Andreis D, Zanoni V, Bazzola L, Bonardi S, Foroni C, Milani M, Cappelleti MR, Gussago F, Aguggini S, Giardini R, Martinotti M, Fox SB, Harris AL, Bottini A, Berruti A, Generali D (2013) Increased pathological complete response rate after long-term neoadjuvant letrozole treatment in postmenopausal oestrogen and/or progesterone receptor-positive breast cancer. Br J Cancer 108:1587-1592. https://doi.org/10.1038/ bjc. 2013.151

16. Toi M, Saji S, Masuda N, Kuroi K, Sato N, Takei H, Yamamoto Y, Ohno S, Yamashita H, Hisamatsu K, Aogi K, Iwata H, Takada M, Ueno T, Saji S, Chanplakorn N, Suzuki T, Sasano H (2011) Ki67 index changes, pathological response and clinical benefits in primary breast cancer patients treated with 24 weeks of aromatase inhibition. Cancer Sci 102(4):858-865. https://doi.org/10 $.1111 / \mathrm{j} .1349-7006.2011 .01867 . x$

17. Olson JA Jr, Budd GT, Carey LA, Harris LA, Esserman LJ, Fleming GF, Marcom PK, Leight GS Jr, Giuntoli T, Commean P, Bae K, Luo J, Ellis MJ (2009) Improved surgical outcomes for breast cancer patients receiving neoadjuvant aromatase inhibitor therapy: results from a multicenter phase II trial. J Am
Coll Surg 208(5):906-914. https://doi.org/10.1016/j.jamcollsur g.2009.01.035

18. Akashi-Tanaka S, Shimizu C, Ando M, Shibata T, Katsumata N, Kouno T, Terada K, Shien T, Yoshida M, Hojo T, Kinoshita T, Fujiwara Y, Yoshimura K (2009) 21-gene expression profile assay on core needle biopsies predicts responses to neoadjuvant endocrine therapy in breast cancer patients. Breast 18(3):171-174. https://doi.org/10.1016/j.breast.2009.03.005

19. Fontein DB, Charehbili A, Nortier JW et al (2014) Efficacy of six month neoadjuvant endocrine therapy in postmenopausal, hormone receptor-positive breast cancer patients-a phase II trial. Eur J Cancer 50:2190-2200. https://doi.org/10.1016/j. ejca.2014.05.010

20. Ueno T, Masuda N, Yamanaka T, Saji S, Kuroi K, Sato N, Takei H, Yamamoto Y, Ohno S, Yamashita H, Hisamatsu K, Aogi K, Iwata H, Sasano H, Toi M (2014) Evaluating the 21-gene assay recurrence score as a predictor of clinical response to 24 weeks of neoadjuvant exemestane in estrogen receptor-positive breast cancer. Int J Clin Oncol 19(4):607-613. https://doi.org/10.1007/ s10147-013-0614-x

21. Barnadas A, Gil M, González S et al (2009) Exemestane as primary treatment of oestrogen receptor-positive breast cancer in postmenopausal women: a phase II trial. Br J Cancer 100(3):442449. https://doi.org/10.1038/sj.bjc.6604868

22. Krainick-Strobel UE, Lichtenegger W, Wallwiener D, Tulusan AH, Janicke F, Bastert G, Kiesel L, Wackwitz B, Paepke S (2008) Neoadjuvant letrozole in postmenopausal estrogen and/or progesterone receptor positive breast cancer: a phase IIb/III trial to investigate optimal duration of preoperative endocrine therapy. BMC Cancer 8:62. https://doi.org/10.1186/1471-2407-8-62

23. Spring LM, Gupta A, Reynolds KL, Gadd MA, Ellisen LW, Isakoff SJ, Moy B, Bardia A (2016) Neoadjuvant endocrine therapy for estrogen receptor-positive breast cancer: a systematic review and meta-analysis. JAMA Oncol 2(11):1477-1486. https://doi. org/10.1001/jamaoncol.2016.1897

24. Paik S, Tang G, Shak S, Kim C, Baker J, Kim W, Cronin M, Baehner FL, Watson D, Bryan J, Costantino JP, Geyer CE, Wickerham DL, Wolmark N (2006) Gene expression and benefit of chemotherapy in women with node-negative, estrogen receptorpositive breast cancer. J Clin Oncol 24(23):3726-3734. https:// doi.org/10.1200/JCO.2005.04.7985

25. Habel LA, Shak S, Jacobs MK, Capra A, Alexander C, Pho M, Baker J, Walker M, Watson D, Hackett J, Blick NT, Greenberg D, Fehrenbacher L, Langholz B, Quesenberry CP (2006) A population-based study of tumor gene expression and risk of breast cancer death among lymph node-negative patients. Breast Cancer Res 8(3):R25. https://doi.org/10.1186/bcr1412

26. Dowsett M, Cuzick J, Wale C, Forbes J, Mallon EA, Salter J, Quinn E, Dunbier A, Baum M, Buzdar A, Howell A, BugariniR BFL, Shak S (2010) Prediction of risk of distant recurrence using the 21-gene recurrence score in node-negative and node-positive postmenopausal patients with breast cancer treated with anastrozole or tamoxifen: a TransATAC study. J Clin Oncol 28(11):18291834. https://doi.org/10.1200/JCO.2009.24.4798

27. Sparano JA, Gray RJ, Makower DF, Pritchard KI, Albain KS, Hayes DF, Geyer CE Jr, Dees EC, Goetz MP, Olson JA Jr, Lively T, Badve SS, Saphner TJ, Wagner LI, Whelan TJ, Ellis MJ, Paik S, Wood WC, Ravdin PM, Keane MM, Gomez Moreno HL, Reddy PS, Goggins TF, Mayer IA, Brufsky AM, Toppmeyer DL, Kaklamani VG, Berenberg JL, Abrams J, Sledge GW Jr (2018) Adjuvant chemotherapy guided by a 21-gene expression assay in breast cancer. N Engl J Med. https://doi.org/10.1056/NEJMoa1510764

28. Albain KS, Barlow WE, Shak S, Hortobagyi GN, Livingston RB, Yeh IT, Ravdin P, Bugarini R, Baehner FL, Davidson NE, Sledge GW, Winer EP, Hudis C, Ingle JN, Perez EA, Pritchard KI, Shepherd L, Gralow JR, Yoshizawa C, Allred DC, Osborne CK, Hayes 
DF, Breast Cancer Intergroup of North A (2010) Prognostic and predictive value of the 21-gene recurrence score assay in postmenopausal women with node-positive, oestrogen-receptor-positive breast cancer on chemotherapy: a retrospective analysis of a randomized trial. Lancet Oncol 11(1):55-65. https://doi.org/10.1016/ S1470-2045(09)70314-6

29. Rakha EA, Reis-Filho JS, Baehner F et al (2010) Breast cancer prognostic classification in the molecular era: the role of histological grade. Breast Cancer Res 12:207. https://doi.org/10.1186/ bcr 2607

30. Ward WH, DeMora L, Handord E, Sigurdson ER, Ross EA, Daly JM, Aggon AA, Bleicher RJ (2020) Preoperative delays in the treatment of DCIS and the associated incidence of invasive breast cancer. Ann Surg Oncol 27:386-396. https://doi.org/10.1245/ s10434-019-07844-4

31. Hwang ES, Hyslop T, Lynch T et al (2019) The COMET (comparison of operative versus monitoring and endocrine therapy) trial: a phase III randomised controlled clinical trial for low-risk ductal carcinoma in situ (DCIS). BMJ Open 9(3):e026797. https ://doi.org/10.1136/bmjopen-2018-026797

32. Kanbayashi C, Thompson AM, Hwang ES et al (2019) The international collaboration of active surveillance trials for low-risk DCIS (LORIS, LORD, COMET, LORETTA). J Clin Oncol. https ://doi.org/10.1200/JCO.2019.37.15_suppl.TPS603

33. Masuda N, Sagara Y, Kinoshita T, Iwata H, Nakamura S, Yanagita Y, Nishimura R, Iwase H, Kamigaki S, Takei H, Noguchi S (2012) Neoadjuvant anastrozole versus tamoxifen in patients receiving goserelin for premenopausal breast cancer (STAGE): a doubleblind, randomized phase 3 trial. Lancet Oncol 13(4):345-352. https://doi.org/10.1016/S1470-2045(11)70373-4

34. Linsk A, Mehta TS, Dialani V, Brook A, Chadashvili T, Houlihan M, Sharma R (2017) Surgical upgrade rate of breast atypia to malignancy: an academic center's experience and validation of a predictive model. Breast J 24:115-119. https://doi.org/10.1111/ tbj. 12885

35. Eby PR, Ochsner JE, DeMartini WB, Allison KH, Peacock S, Lehman CD (2008) Frequency and upgrade rates of atypical ductal hyperplasia diagnosed at stereotactic vacuum-assisted breast biopsy: 9- Versus 11-Gauge. AJR Am J Roentgenol 192:229-234.

36. Lamb LR, Bahl M, Hughes KS, Lehman CD (2018) Pathologic upgrade rate of high-risk breast lesions on digital two-dimentional vs tomosynthesis mammography. J Am Coll Surg 226:858-867

37. Ravdin PM, Siminoff LA, Davis GJ et al (2001) Computer program to assist in making decisions about adjuvant therapy for women with early breast cancer. J Clin Oncol 19:980-991. https ://doi.org/10.1200/JCO.2001.19.4.980

38. American College of Surgeons, American Society of Anesthesiologists, Association of Perioperative Registered Nurses, American Hospital Association. (2020) Joint Statement: Roadmap for Resuming Elective Surgery after COVID-19 Pandemic https:// www.aha.org/system/files/media/file/2020/04/roadmap-from-ahaothers-for-safely-resuming-elective-surgery-as-covid-19-curve -flattens.pdf

39. COVID-19 Pandemic Breast Cancer Consortium's Considerations for Re-entryhttps://www.surgonc.org/wp-content/uploa ds/2020/05/COVID-BC-Reentry-Paper-May 15_0100P_Clean .pdf?_zs=r7ljB1\&_zl=PP5m5

Publisher's Note Springer Nature remains neutral with regard to jurisdictional claims in published maps and institutional affiliations. 